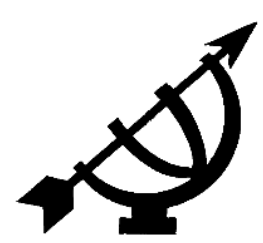

\title{
Een concentratieprobleem bij B.J. van der Walt
}

\author{
S. Griffioen 1 \\ Emeritus: Wijsbegeerte \\ Vrije Universiteit \\ AMSTERDAM \\ E-mail: veelzicht@planet.nl
}

\section{Abstract \\ B.J. van der Walt's concentration problem}

This contribution probes the concept of secularism, a key notion of B.J. van der Walt's "Transforming power" (2007). It is found that Van der Walt's interpretation of secularism rests on a double assumption. The first assumption is that human nature is intrinsically religious. Humans cannot live without putting their trust in something. The second is that this religious nature manifests itself in "concentrated" ways, rather than dispersing itself over a plurality of objects. These assumptions in tandem explain why Van der Walt holds the view that atheism, agnosticism and even overt indifference in matters of faith are at heart propelled by convictions that share the main features of positive religions. It also explains why he assumes that all these convictions tend towards one and the same goal: to gain dominance in the public realm.

This article is sympathetic towards the first assumption, and skeptical towards the second. It is argued that the "concentration-thesis" fails to do justice to world and life-views that obviously do not claim total allegiance. To illustrate this point it turns to the phenomenon of "multiple religious participation", as well as to different strands within contemporary humanism. It concludes that the main problem may well be that secular culture has little to offer to satisfy the innate religious drive in humankind.

$1 \quad$ Ik dank de keurders van dit tijdschrift voor nuttige aanwijzingen tot verbetering. Keurder $\mathrm{C}$ dank ik bovendien voor suggesties voor een vervolg discussie. 
Finally, an attempt is made to amend the notion of secularism in such a way as to steer clear from "Konsequenzmacherei".

\section{Samenvatting}

\section{Een concentratieprobleem bij B.J. van der Walt}

Deze bijdrage onderzoekt een dubbele veronderstelling van de benadering van secularisatie en secularisme in B.J. van der Walt's "Transforming power" (2007). De eerste veronderstelling is dat de menselijke natuur intrinsiek religieus is, in de zin dat niemand kan leven zonder zich aan iemand of iets toe te vertrouwen. De tweede aanname, door mij aangeduid als de "concentratie these", is dat de religieuze impuls normaliter zich in geconcentreerde vorm uit, in plaats van zich over meerdere objecten te verdelen. Op grond van beide vooronderstellingen herleidt Van der Walt atheïsme en zelfs godsdienstige onverschilligheid tot overtuigingen die qua intensiteit met geloofsovertuigingen overeenstemmen en evenals de laatste naar hegemonie streven op het publieke terrein.

$\mathrm{Na}$ het analytische deel volgt een eigen stellingname. De schrijver van deze bijdrage staat sympathiek tegenover de eerste aanname, maar verwerpt de tweede. Het voornaamste argument is dat de concentratie these geen recht doet aan het verschijnsel van wereld- en levensbeschouwingen die het leven van aanhangers niet volledig in beslag nemen. Deze stelling wordt uitgewerkt in een beschouwingen over het hedendaagse humanisme en het verschijnsel van "multiple religious participation".

\section{Vooraf}

Het is een eer mee te mogen werken aan dit speciale nummer voor vriend Bennie van der Walt. De herinneringen aan hem gaan terug tot de tijd dat we samen bij prof. S.U. Zuidema colleges volgden over Thomas, De ente et essentia. Dat zal in 1967 zijn geweest. Verder bewaar ik goede herinneringen aan ontmoetingen van uiteenlopende aard, waar onder binnen het verband van de International Association for the Promotion of Christian Higher Education (IAPCHE). Graag verbind ik aan dit artikel mijn persoonlijke gelukwensen.

Bennie is ongeveer de laatste persoon met wie je van mening zou willen verschillen, en toch voelde ik een verschil van inzicht opkomen bij gebruik van zijn Transforming power (Van der Walt, 2007) als verplichte lectuur bij mijn colleges voor de opleiding International Master Christian Studies aan de Vrije Universiteit. Al hoewel geheel geestverwant in de hoofdzaken, ervoer ik de duiding van secularism 
als te massief. De kwestie kwam vervolgens in beknopte vorm aan de orde in een opstel over secularisatie voor Philosophia reformata (Griffioen, 2008:71-84). Bij de bespreking van Hendrk van Riessens visie op secularisatie trok ik een lijn door naar Van der Walt. Het ging om de stelling dat achter de schijn van godsverduistering een (anti-)geloof schuil gaat. Van Riessen en Van der Walt gaan ervan uit dat de behoefte in "iets" te geloven tot de menselijke natuur behoort en dat dus achter de geseculariseerde mens nog altijd een "gelovige" schuilgaat, dit wil zei iemand die nog steeds ergens zijn ankers uitgooit, vertrouwend er houvast te vinden. Hier nam mijn betoog een kritische wending. Wat ik wilde problematiseren is een assumptie die bij beiden met de zojuist genoemde gepaard gaat, te weten dat aan alle geloof - ook het ongelovige geloof - een concentratietendens eigen is. De veronderstelling is dat de geseculariseerde mens nog altijd naar een laatste houvast zoekt en bewust of onbewust daarop al zijn strevingen concentreert. Ongeloof vormt zo bezien het negatieve spiegelbeeld van geloof. Aldus vallen ongeloof en positief geloof onder de ene categorie "geloof".

In het genoemde artikel werd alleen een begin gemaakt met deze kritische bevraging. De huidige bijdrage beoogt deze argumentatie voort te zetten in een dialoog met Transforming power. Begonnen wordt met een bespreking van wat dit boek inzake secularism leert. Daarop volgt een verdieping en uitbreiding van wat in het eerder genoemde artikel al ontwikkeld was. Het slotgedeelte nuanceert de gerezen verschillen door te onderscheiden tussen tweeërlei gebruik van de concentratie-these en maakt zo de weg vrij voor een herformulering van Van der Walts secularisatietheorie die het wezen ervan bewaart en de door mij verwoorde bezwaren wegneemt.

\section{Transforming power}

\subsection{Introductie}

Transforming power beschouwt secularisme als de meest kenmerkende uiting van de geest van deze tijd (Van der Walt, 2007:223). Van der Walt vreest dat in Zuid Afrika velen blind voor deze tijdgeest zijn. Als historische verklaring draagt hij aan dat in de periode van voor 1994 een façade van christelijke waarden was opgetrokken waardoor secularisatie allereerst een gevaar scheen dat van buitenaf de Zuid-Afrikaanse samenleving bedreigde. Hierdoor bleven velen blind voor wat van binnenuit kwam. Na 1994, schrijft Van der Walt "the Afrikaners no longer had the political power to further their Christian convictions"; eerst toen vielen de schellen van de ogen en zag men met schrik hoe geseculariseerd de eigen samenleving in 
feite was geworden. Maar ook sindsdien weten slechts weinigen het gevaar tot in de diepte te peilen (Van der Walt, 2007:225).

Secularisatietheorieën zijn volgens Van der Walt mede debet aan deze kortzichtigheid. Zij concentreren zich op uitwendige verschijnselen zoals dalend kerkbezoek (Van der Walt, 2007:228), en concluderen dat de religiositeit afneemt, zonder op te merken dat secularisme zelf een (tegen-)religie is. Onder deze theoretici vormt Peter Berger een uitzondering in zoverre hij erkent dat de mens van nature religieus is: "man is inherently a religious being who consequently seeks for sense and meaning which goes beyond his empirical existence", zo geeft de schrijver diens opvatting weer (Van der Walt, 2007:229). Om het secularisme te weerstaan, is het eerst nodig religie en tegen-religie in hun radicaliteit te peilen. De crux is dat de mens als religieus wezen is geschapen en dat dus een religieuze oriëntatie - zij het op God of afgod gericht - de levensrichting bepaalt (Van der Walt, 2007:233).

\subsection{Secularisme in geconcentreerde vorm}

In deze samenhang stuiten we ook op wat ik zo-even een bijkomende assumptie noemde, namelijk dat niet alleen aan (positieve) religie, maar ook aan haar substituut een eenheidsstreven inherent zou zijn. Ten aanzien van ons onderwerp betekent het om te beginnen dat de verschijnselen die we tezamen als "secularisatie" aanduiden op een dieper liggend "secularisme" worden betrokken. Het betekent verder dat dit secularisme als een reële kracht wordt beschouwd; een kracht die zich naar buiten toe ook als zodanig doet gelden.

Hiermee zijn "nominalistische" duidingen afgewezen. Voorbeelden van zulke interpretaties zijn wel te bedenken. Zo zou men secularisme als een "container-begrip" kunnen beschouwen, dit wil zeggen als een verzamelbegrip voor diverse verschijnselen die door niet meer dan familieverwantschappen bijeen worden gehouden, en bij nauwkeuriger onderscheiden wellicht zoveel onderlinge verschillen laten zien dat ze met evenveel zo niet meer reden onder verschillende categorieën gesubsumeerd hadden kunnen worden. Een tweede mogelijkheid, die dichter in de buurt van Van der Walt blijft, is te onderscheiden tussen "drijfveer" en "uitingen". Men kan enerzijds (met B.J. van der Walt) van een geconcentreerde religieuze drijfveer uitgaan, en toch ten aanzien van de uitwerking een meer nominalistische visie ontwikkelen. Later meer hierover.

The Transforming power veronderstelt een concentratietendens zowel in drijfveer als uitingen, en komt aldus tot de stelling dat het 
secularisme een totaal beslag op het leven wil leggen en als alle religie meer wil zijn dan een private overtuiging: "It pursues the ideal (at least in the public field) of being the dominant faith" (Van der Walt, 2007:233).

\subsection{Postmodernisme als testcase}

Het wordt spannend waar het postmoderne levensklimaat aan de orde komt. Kan in dit klimaat wel een eenheidsstreven gedijen? Is het niet veeleer zo dat het diversiteit tolereert, zo niet prijst, en al wat zich als meerduidig voordoet bejubelt? Of moeten we aannemen dat deze veelgenoemde postmoderne "openheid" een façade is waarachter nog wel degelijk een eenheidsstreven schuil gaat? Het verbaast niet dat Van der Walt de laatstgenoemde conclusie trekt. Het is zijn overtuiging dat het postmoderne levensklimaat in vergelijking tot de modernistische mentaliteit zelfs een extra gevaar in zich bergt. Ja zeker, een bepaalde welwillendheid ten opzichte van religieuze diversiteit wil hij niet ontkennen (Van der Walt, 2007:258). Maar of er nu ook sprake is van een principiële wending ten opzichte van het modernistische ongeloof? Hij waagt het te betwijfelen. Het postmodernisme is slechts een nieuwe variant van secularisme. Vergissen we ons niet dan beschouwt hij de postmoderne openheid voor diversiteit eerder als een gevaar ( $\mathrm{nl}$. als aanleiding tot verslapping van waakzaamheid) dan als een wending ten goede.

Nu een mogelijke tegenwerping. Ook wie met de auteur instemt dat het naïef zou zijn de postmoderne geest als een bondgenoot te begroeten (bijv. omdat men er een drijfveer achter vermoedt die niet uit God is), kan zeer wel met hem verschillen ten aanzien van de stelling dat deze geest slechts een nieuwe vorm van secularisme zou zijn. "Postmodernism is merely a new form of secularism and thus cannot be seen as an ally of Christians against secularism." (Van der Walt, 2007:260.) Men kan dus met Van der Walt in de postmoderne tijdgeest een doorwerking en versterking van seculariserende krachten zien, en tegelijk van oordeel zijn dat deze geest zo weinig samenbindend vermogen heeft dat per saldo de oppositie tegen het christelijke geloof aan eenduidigheid inboet. Wie deze redenering volgt, zal ook de mogelijkheid van partiële bondgenootschappen niet op de voorhand willen uitsluiten.

\subsection{Humanisten in soorten}

Ik geef het voorbeeld van de Humanistische beweging in Nederland. Hierbinnen tekenen zich ten aanzien van ons onderwerp twee kampen af, met daarbinnen nog weer significante verschillen. De 
meeste aandacht trekken de voorstanders van terugdringing van de publieke invloed van religie. 2 Anderzijds zijn er misschien wel evenveel humanisten die een neutrale staat een schrikbeeld noemen en het neutraliteitsstreven van de eerst bedoelden soms meer duchten dan de "terugkeer van religie in het publieke domein".3 Deze positieve houding kan evenwel weer verschillend gemotiveerd zijn. Niet zelden is het motief een verdediging in algemene zin van de vrijheid van meningsuiting op het publieke terrein - een vrijheid waaronder zowel godsdienstige als anti-godsdienstige uitingen vallen. Maar er zijn er wel degelijk ook die religieuze inspiratie voor onmisbaar houden en er geen moeite mee hebben dat het humanisme zelf tot de religieuze stromingen wordt gerekend. (Overigens moet bij dit laatste wel rekening worden gehouden met een zeker opportunisme: het is in Nederland nu eenmaal zo dat door zich te voegen in het landschap van religieuze stromingen het humanisme heeft kunnen profiteren van bestaande faciliteiten binnen de publieke orde. Zo hebben we nu humanistische geestelijke verzorging in het leger en in gevangenissen, alsmede een van overheidswege gesubsidieerde opleiding voor humanistische raads-

2 Kenmerkend is de volgende reclameboodschap die de Nederlandse publieke omroep met enige regelmaat uitzendt. Op de binnenkomer "het geluid van religie klinkt tegenwoordig steeds luider" volgt een oproep de humanistische keuze voor menselijke verantwoordelijkheid metterdaad te steunen. De tekst eindigt met: "anders zijn we helemaal aan de goden overgeleverd".

3 Over deze controverse zie bijv. dit bericht in De Volkskrant, (Dohmen \& Manschot, 2007): Amanda Kluveld en Rozemarijn Schalkx geven een verkeerd advies aan het hedendaags humanisme. Dat stellen Joep Dohmen en Henk Manschot vandaag in De Volkskrant. Kluveld (historicus) en Schalkx (tot voor kort verbonden aan de Universiteit voor Humanistiek, UvH) schreven op 5 mei dat het humanisme er goed aan zou doen zich niet langer als surrogaatreligie te gedragen. De kernopdracht ligt volgens Kluveld en Schalkx "in het bewaken van het beginsel van de scheiding tussen kerk en staat, het bepleiten van een seculiere neutrale staat en de bescherming van het individu". Zij noemen de Universiteit voor Humanistiek als een van de aanstichters van het aanschurken tegen religies. Volgens Dohmen, universitair docent aan de UvH, en Manschot, emeritus hoogleraar filosofie en directeur van het UvH-instituut Kosmopolis lijken "de auteurs in de verste verte niet te beseffen dat humanisme en religies door de globalisering de laatste decennia in een volstrekt nieuwe situatie zijn beland".

Kluveld en Schalkx radicaliseren volgens Dohmen en Manschot de tegenstelling tussen humanistisch-seculier versus religieuze culturen en dragen zo bij aan het denken in "wij tegen zij". Het gaat in de huidige samenleving al lang niet meer om een tegenstelling tussen humanisme en religie, stellen Dohmen en Manschot. "Het gaat om een houding die weigert een samenleving te creëren met andersdenkenden tegenover een houding die democratie, dialoog en pluraliteit voorstaat." 
lieden die helemaal gemodelleerd is naar de predikantsopleidingen, enz.) Tenslotte vinden we onder de humanisten een minderheid die, ofschoon zelf agnostisch ten aanzien van het Godsbestaan, de invloed van het christendom voor het voortbestaan van de Westerse cultuur van essentieel belang acht. Tot die laatsten behoort bijvoorbeeld Anton Zijderveld, cultuur-socioloog en tot voor kort prominent lid van het CDA (Christen-Democratisch Appel, lang de grootste regeringspartij). Mijn vraag luidt: kan "secularisme" in de zin van Bennie van der Walt recht doen aan deze schakeringen? Zijn over de hele linie bondgenootschappen uit te sluiten? ${ }^{4}$

\section{Concentratie en divergentie}

\subsection{Werkzame schijn}

In het Philosophia reformata artikel kwam Transforming power zoals gezegd zijdelings aan de orde in een beschouwing die aan Hendrik van Riessens secularisatietheorie was gewijd. Wat Van Riessens benadering onderscheidt, is dat hij de secularisatie tot in de structuren van samenleving en techniek aanwijst, ja zelfs tot in de technische apparatuur. Het gaat hem hierin vooral om de rol van de wetenschap. Wetenschap abstraheert met een zeker recht van Gods presentie in de leefwereld. Het probleem begint waar wetenschap zich tot wereldbeeld ontwikkelt en kennis die door abstractie was verkregen voor bij uitstek betrouwbaar wordt gehouden. Wat schijn is (nl. dat het Godsbestaan er niet toe doet) krijgt het keurmerk van bewezen waarheid. Over de boog van toegepaste wetenschap kan deze schijn zich vervolgens tot in de structuur van de artefacten vastzetten (zie Van Riessen, 1967:25-54, 101-123).

Als ongeloof zich tot in de dingen breed maakt en dan ook langzaam maar zeker als een normaal wordt ervaren, ligt het gelijk dan toch niet aan de kant van secularisatietheorieën die een afname van religie voorspellen? Van Riessens antwoord is genuanceerd, want behelst een ja en een nee. Ja, want de schijn dat, grof gezegd, God er niet toe doet, is werkzaam: het is geen hersenschim zonder realiteitswaarde. Het is ook geen ideologie die een samenleving op

4 Voor een vorm van samenwerking op het filosofische vlak, zie Brugmans (2002). Behalve als één van de negenentwintig auteurs, was ik ook referent namens de Stichting Reformatorische Wijsbegeerte, en als zodanig nauw bij de totstandkoming van dit boek betrokken. De samenwerking met het Humanistisch Verbond is van begin tot einde goed geweest. De eerlijkheid gebiedt wel te zeggen dat er moeite waren met betrekking tot uitgesproken secularistische opvattingen van tenminste één humanistische auteur. 
afstand kan proberen te houden door om zich heen de façade van een civil religion op te richten. Nee, omdat, hoe werkzaam ook, de schijn toch schijn blijft.

Door de werkzaamheid te benadrukken, wil Van Riessen zijn lezers ervan doordringen de ernst van de situatie niet te onderschatten: de genoemde schijn wint met de dag aan plausibiliteit. Het ligt in zijn lijn te zeggen dat theorieën die secularisatie aan dalend kerkbezoek afmeten, aan de oppervlakte blijven en zich op uiterlijke symptomen blindstaren. Als het om diepte gaat, komt Van Riessen (net als Van der Walt trouwens) bij een geloof uit. Het is het geloof dat wetenschap de laatste arbiter is in zaken van wat waar is en wat niet. Dat wetenschap zo het laatste woord verkrijgt, is omdat mensen er hun hart op zetten. En waarom ze dit doen? Omdat ook zij van nature religieus zijn.

Hetzelfde artikel gaf voorbeelden die laten zien dat de term secularisme al in de negentiende-eeuwse Engelssprekende wereld op ongeveer dezelfde wijze gebruikt werd als nu door Van der Walt. De secularisme kritiek heeft dus oude papieren, en is bepaald niet alleen een specialiteit van calvinistisch-wijsgerige huize! In dit verband werd ook gewezen op een parallel met de kritiek van een Neuhaus op het neutraliteitsideaal. Hier is de passage over diens.

Men zal er een vergelijkbare secularisme-kritiek vinden, maar dan afgestemd op de Noord-Amerikaanse situatie. De teneur is evenzeer dat neutraliteit een onmogelijke droom is. Het publieke terrein blijft volgens Neuhaus nooit lang leeg: is de ene religie verdwenen, dan wordt het vacuüm door een volgende opgevuld. (cf. Neuhaus, 1984:74.)

\subsection{In de verstrooiling}

Wat we bij Bennie van der Walt vinden, is dus ten volle waard serieus te worden genomen. Dat het Philosophia reformata-artikel niettemin een kritische wending nam, is vanwege de sterke versie van de concentratiethese, een kwestie die boven al werd aangeroerd.

De aanleiding tot de formulering van een afwijkende visie lag in het verschijnsel dat bekend staat als "multiple religious participation" (MRP) - het fenomeen dat iemand zich tot meer dan één godsdienst bekent. Ik werk dit nu verder uit.

Zoals bekend is in China (en breder: het Verre Oosten) het verschijnsel wijd verbreid dat personen zowel aan confuciaanse, 
taoïstische als aan boeddhistische rituelen deelnemen (Griffioen, 2006). Wij zijn geneigd dit verschijnsel als syncretisme te duiden. De Chinese (in Amerika levende) filosoof Chenyang Li betoogt echter dat dit onjuist is, aangezien er geen vermenging van religies plaatsvindt. Let er op hoe hij MRP en syncretisme onderscheidt:

Multiple religious participation, however, is different from syncretism. People of multiple religious participation practice more than one religion with a recognition that these are different. They do it without making an effort to integrate them into one single religion on the basis of some common tenets. (Li, 1999:151.)

Nu kan het zijn dat Chinese bronnen de neiging hebben MRP te ideaaltypisch te duiden, als zou in deze praktijk elk eenheidsstreven ontbreken en als zouden de verschillende rituelen keurig gescheiden blijven. Enige scepsis lijkt me hier wel op zijn plaats. Maar dan blijft nochtans overeind dat geen van deze rituelen een totaal beslag legt op de deelnemer. Zoals ik zelf meemaakte als gast van een Taiwanese familie, heeft men bij het overlijden van een familielid de keuze uit confuciaanse en taoïstische rituelen, en kan men ook nog boeddhistische voorschriften inzake rouw volgen, zonder naar eigen besef ook maar ergens aan de integriteit van één van deze religies tekort te doen. Dit wil niet zeggen dat de gezindheid van het hart er niet toe doet. In tegendeel, oprechtheid is een voorwaarde voor het welslagen van de rituelen. Saillant gegeven is evenwel dat geen van deze religies een totaal beslag op het leven beoogt te leggen. Het "geen duimbreed" uit Kuypers rede over "Souvereiniteit in eigen kring" vindt hier geen pendant!

\subsection{Onbepaaldheid}

Hoe ligt dit bij de monotheïstische religies: christendom, islam en judaïsme? Ook hier komt "multiple religious participation" voor. Het is niet voor niets dat Ellis en Ter Haar (2004), schrijvend over religies en machten in Afrika, dit fenomeen van meet af op christendom en islam betrekken.

Plural religious allegiance is common, with individuals frequenting several religious communities at once or practicing rituals regarded in the west as belonging to different or competing systems of belief, such as Christianity and Islam, or Christianity and 'traditional' religion. (Ellis \& Ter Haar, 2004:51.)

Het verschil ten opzichte van de oude religies van het Oosten is evenwel dat het nu een niet-normaal verschijnsel betreft. MRP komt 
voor, maar gaat duidelijk tegen de norm in. De norm is onvoorwaardelijke toewijding tot de religie die men kiest. In deze absoluutheid ligt, historisch gezien, het voornaamste verschil tussen West en Oost.

Maar nu moeten we oppassen voor (verkeerde) Konsequenzmacherei. Gaat men er eenmaal van uit dat de menselijke natuur onuitwisbaar religieus is: wat ligt dan meer voor de hand dan ook aan te nemen dat idolen, ideologieën en "-ismen"5 die in confrontatie en wisselwerking met (vooral) de christelijke religie zijn opgekomen in principe ook in haar absoluutheid delen en op vergelijkbare wijze van hun volgelingen totale toewijding vragen? De aanname ligt inderdaad voor de hand, maar is toch niet zonder meer gewettigd. Neem opnieuw het Nederlandse humanisme: beschouwen we het als spiegelbeeld van christelijk geloof, dan zullen we voetstoots aannemen dat het in principe van zijn volgelingen een onvoorwaardelijke commitment vraagt, en verder dat het "genoeg in huis heeft" om die toewijding zinvol te doen schijnen. Ik betwijfel zowel het een als het ander. In de eerste plaats zijn me geen voorbeelden bekend van absolute claims. In de tweede plaats is het dubieus of het voldoende substantie heeft om zich tot een omvattende leer of ideologie te kunnen ontwikkelen. Moet je niet veeleer stellen dat het de religieuze aandrift niet kan bevredigen en zelfs geen sluitende "humanistische wereldbeschouwing" heeft aan te bieden?

Als bijzonder hoogleraar Reformatorische wijsbegeerte te Leiden (1979-1990) had ik regelmatig contact met Marcel Fresco, bezetter van de humanistische leerstoel "Socrates". Rond 1985 organiseerden wij een publieke discussie, waaraan ook Paul van Tongeren deelnam, de houder van de Radboud-leerstoel voor katholieke filosofie. Met een minimum aan bekendmaking kregen we de zaal vol. Mijn uitgangsstelling in de discussie was dat iedereen, ook Fresco, een wereldbeschouwing heeft. Diens reactie was bijna wanhopig: "elke keer dat ik met een calvinist debatteer moet ik opnieuw uitleggen dat ik geen wereldbeschouwing heb". Dit was een understatement, want ik kende hem goed genoeg om te weten dat hij zich in zijn werk en leven door humanistische beginselen liet leiden. De waarheid was evenwel dat hij geen volledige wereldbeschouwing

5 Gemakshalve onderscheid ik niet tussen idolen (verabsoluteerde sport, sex, gezondheid, wetenschappelijke kennis, enz.), ideologieën (gelieerd aan maatschappelijke bewegingen) en -ismen (fysicalistische, materialistische, psychologistische, logicistische, historistische, etc., wereldbeelden). 
bezat. Was het daarom achteraf gezien niet beter geweest te beginnen met de vraag of het humanisme wel in staat is een all-round wereldbeschouwing te leveren en of het niet waar 't aankomt op vragen van leven en dood zijn aanhangers, met inbegrip van Marcel Fresco, in de kou laat staan?

\section{Tweërlei gebruik van de concentratie-these}

Terug naar secularisme. De lezer zal zich inmiddels afvragen of deze auteur de term nog wel kan blijven gebruiken. Is op mijn standpunt de term zelf niet al een probleem? Het antwoord is ja en nee. Ja, in de zin dat het gebruik geproblematiseerd dient te worden. Nee, als bedoeld zou zijn dat secularisme voortaan geheel onbruikbaar is. Problematisch is slechts de onkritische aanname van een concentratietendens in secularisatie-verschijnselen. Hiermee wil helemaal niet gezegd zijn dat deze tendens zich niet kan voordoen. Ook naar mijn oordeel zijn er tekenen die in die richting wijzen (naast andere waarvan ik dat betwijfel). Hier zij herinnerd aan het slotgedeelte van een recente bijdrage voor Woord en daad. Het ging er om openingen en moeiten voor reformatorische filosofie in Nederland. Als voorbeeld van moeite werd het verlies van twee bijzondere leerstoelen genoemd, naast de moeite door te dringen tot de kolommen van de glossy filosofische magazines en de prestigieuze fora. $\mathrm{Na}$ erkenning van tekortkomingen aan Reformatorische zijde, wees ik toch secularisme aan als de belangrijkste factor:

Maar als alles gezegd en gedaan is, blijft er toch een voorname (m.i. voornaamste) factor ongenoemd, en die is van geestelijke aard: het is de geest van secularisme die geen integraal christelijke visie naast zich verdraagt. (Griffioen, 2009:38.)

Zo komen we tenslotte uit bij tweeërlei gebruik van de concentratiethese. De ene is de strikte modus, leunend op de gedachte dat (positieve) religie altijd een totaal beslag legt op het leven van haar volgelingen, en dat idolen hiervan een spiegelbeeld vormen. De andere is de kritische, die zich tot een restrictief gebruik beperkt. Het kan dan gaan om een lezen van zichtbare tekens en duiding van een actuele tendens, maar ook zeer wel om een concentratie-tendens die voor het blote oog niet zichtbaar is en alleen op het radarscherm van geestelijke verbeelding verschijnt.

Dit laatstgenoemde is belangrijk. Zoals het voorbeeld van het Nederlandse humanisme duidelijk maakte, ontbreekt het substituten voor het christelijk geloof veelal aan substantie om de religieuze honger te kunnen bevredigen. Daardoor ontwikkelen zich labiele 
ideologische systemen in de samenleving, die als zodanig de mogelijkheid van radicalisering in zich dragen. Waar het blote oog niets ontwaart dan voortgaande verbijzondering en fragmentarisering ziet, kan een geestelijke verbeeldingskracht al een geconcentreerde anti-religie zien opdoemen. In deze zin heeft secularisme een belangrijke attenderende waarde.

Van harte wens ik Transforming power een tweede editie toe. Zou de auteur het gebruik van de concentratie-these in boven bedoelde zin problematiseren, dan voorspel ik dat dit werk nog verder aan overtuigingskracht zal winnen.

\section{Geraadpleegde bronnen}

BRUGMANS, E., red. 2002. Cultuurfilosofie, katholieke, reformatorische, humanistische, islamitische en joodse reflecties over onze cultuur. Open Universiteit: Damon, Budel.

DOHMEN, J. \& MANSCHOT, H. 2007. Verkeerd advies aan hedendaags humanisme. De Volkskrant: Het Betoog, 26 mei.

ELLIS, S. \& TER HAAR, G. 2004. Worlds of power: religious thought and political practice in Africa. London: Hurst.

GRIFFIOEN, S. 2006. Multiple religious participation in China: a philosophical puzzle. (In Goheen, M. \& O'Gara, M., eds. That the world may believe: essays on mission and unity in honour of George Vandervelde. Lanham: University Press of America. p. 67-81.)

GRIFFIOEN, S. 2008. Secularisme en secularisatie. Philosophia reformata, 73:71-84.

GRIFFIOEN, S. 2009. Reformatorische filosofie in Nederland: openingen en moeiten. Woord en daad, 49(407):35-38.

LI, C. 1999. The Tao encounters the West: explorations in comparative philosophy. Albany: SUNY.

NEUHAUS, R.J. 1984. The naked public square. Grand Rapids: Eerdmans.

VAN DER WALT, B.J. 2007. Transforming power: challenging contemporary secular society. Potchefstroom: Institute for Contemporary Christianity in Africa.

VAN RIESSEN, H. 1967. Mondigheid en de machten. Amsterdam: Buijten \& Schipperheijn. (Reeks Christelijk Perspectief.)

\section{Kernwoorden}

concentratie-these: reformatorische wijsbegeerte

humanisme als religie

religieuze menselijke natuur

secularisatietheorie

secularisme 


\section{Key concepts:}

concentration-theme: reformational philosophy

human nature as intrinsically religious

humanism as a religion

secularisation theory

sekularisme 
